\title{
A negligência parental e a relação com a deficiência: o que mostra a pesquisa nacional
}

Mara Silvia Pasian*

\section{Resumo}

Os maus-tratos da criança e do adolescente podem ocasionar diversas consequências negativas para o desenvolvimento infantil, sendo que, em determinadas situaçôes, pode ser gerada alguma deficiência para essa criança por falta de cuidados ou pela violência gerada contra ela, alguns casos podem levar até ao óbito. O objetivo do presente trabalho foi investigar material divulgado na realidade brasileira que envolva a temática de maus-tratos-infantis, especificamente na modalidade da negligência, e que abordassem de alguma forma os termos deficiência ou necessidades especiais. Para isso, foi feita uma busca nas bases de dados SCIELO e LILACS sem restriçáo de período, os artigos selecionados encontraram-se entre os anos de 2000 e 2010. Em seguida, foram selecionados e analisados de forma qualitativa 12 artigos completos. Os resultados dessa pesquisa revelam que os artigos analisados centralizaram sobre a temática da descriçáo dos tipos de maus-tratos e sobre a necessidade de maior conscientização e notificação dos casos. Dois artigos abordaram a relação dos maustratos infantis e a deficiência, mostrando significativa vulnerabilidade da criança com deficiência para ocorrência de abuso ou negligência parental. Como consideraçóes, sugere-se produção de pesquisas e divulgação de estudos que envolvam a temática da negligência infantil e o indivíduo com necessidades especiais, focando suas consequências e medidas de prevenção.

Palavras-chave: Maus-tratos infantis; Desenvolvimento da criança; Deficiência.

* Tutora virtual da Universidade Aberta do Brasil - Universidade Federal de São Carlos, São Carlos, São Paulo, Brasil. 


\section{The parental negligence and relationship with disabilities: what does the national survey shows}

\section{Abstract}

Child maltreatment can cause several negative consequences for development, and, in certain situations, can be generated for any deficiency that child from neglect or violence generated against it, and some cases may lead to death. The objective of this study was to investigate material published in the Brazil involving the theme of maltreatment and child, specifically in the form of child neglect and somehow that addressed the terms disabilities or special needs. For this was made a search in databases and SCIELO LILACS, without restriction period, the articles selected are between the years 2000 and 2010. Then were selected and analyzed qualitatively 12 full articles. The results of this research show that the analyzed articles centered on the theme of the description of the types of abuse and the need for increased awareness and reporting of cases involving child abuse, two articles address the relationship of child maltreatment and disability, showing significant vulnerability of children with disabilities for the occurrence of parental abuse or neglect. The considerations point to the need research production and dissemination of studies involving the issue of child neglect and the individual with special needs, focusing consequences and prevention measures.

Keywords: Child abuse; Childhood development; Disability.

\section{Introdução}

O presente trabalho visou descrever e discutir sobre as produçóes científicas nacionais que envolvem a temática de maus-tratos infantis, especificamente na modalidade negligência parental. Aborda o que esses estudos relatam sobre a relação com a deficiência, que pode ser um fator de vulnerabilidade para a criança e em alguns casos favorece para que a mesma seja maltratada ou negligenciada de forma mais acentuada.

Como relata Williams (2003):

O indivíduo (portador) de deficiências de qualquer modalidade - seja visual, auditiva, física ou mental - encontra-se em uma posição de grande vulnerabilidade em relaçáo ao não (portador), sendo frequentemente marcante a assimetria das relaçóes de poder na interação entre ambos. Tal "assimetria de relação hierárquica" é multiplicada, conforme a severidade de cada caso, sendo ampliada se o (portador) de necessidades especiais pertencer a um outro grupo de risco, como por exemplo, se for mulher ou criança. (termo original do texto, terminologia não mais utilizada). (WILLIAMS, 2003, p. 142).

Em consonância com essa colocação, podemos afirmar que a criança com necessidades especiais torna-se mais vulnerável, assim como o próprio fato de ser criança, aumentando a possibilidade da ocorrência de maus-tratos. Torna-se relevan- 
te colocar que, em alguns casos, o abuso ou a negligência ocasionada pelos pais ou cuidadores pode ocasionar alguma deficiência, seja por falta de cuidados, seja pela violência despendida pelos mesmos (CRUZ; SILVA; ALVES, 2007; LACHARITÉ; ETHIE; NOLIN, 2006; PASIAN, 2004)

A Organização Mundial da Saúde e a Sociedade Internacional para a Prevenção do Abuso e da Negligência Infantil (WHO; ISPCAN) definem maus-tratos infantis como a violência praticada contra as crianças, em âmbito doméstico, geralmente pelos cuidadores principais, sendo uma das formas de violência mais graves, pelo número de vítimas que faz e pelas sequelas que deixa. Ainda segundo tais organismos, os maus-tratos implicam em formas diversificadas de abusos físico, emocional e/ou sexual, além da negligência e da exploração, e oferece dano real ou potencial à saúde, à sobrevivência, ao desenvolvimento ou à dignidade da criança (WHO; ISPCAN, 2006).

O presente trabalho toma a negligência infantil como tema central do estudo implementado, destacando-se que ela é a modalidade de maus-tratos mais recorrente em todo mundo, incluindo o Brasil. Destaca-se que a mesma é causadora de inúmeras consequências negativas para o desenvolvimento de crianças e adolescentes (ROQUE; FERRIANI, 2007; BAZON, 2008; FERREIRA, 2005; PASIAN, 2012; PIRES; MIYAZAKI, 2005).

\section{Definição da negligência infantil}

Podemos considerar que a negligência se configura quando os pais, frequentemente, não têm vontade/disposição ou capacidade psicológica requerida para cuidar da criança e, dessa forma, acabam respondendo inadequadamente às necessidades de seus filhos e não demandam ou não conseguem aproveitar da ajuda de outras pessoas que poderiam/deveriam ajudar (PASIAN et al, 2015). Envolve situaçóes crônicas de falta de cuidados que podem afetar o desenvolvimento da criança, como falta de frequência na escola, não impor limites, falta de convívio social, não proporcionar alimentaçáo, vestimenta e condiçóes de higiene adequadas.

A negligência infantil, numa definição geral feita recentemente pela Organização Mundial da Saúde e a Sociedade Internacional para a Prevenção do Abuso e a negligência Infantil (WHO; ISPCAN, 2006), buscando congregar parâmetros relativos à conceituação e ao manejo dos maus-tratos infantis, define que a negligência inclui tanto eventos isolados como um padrão de cuidado estável no tempo por parte dos pais e/ou outros membros da família, pelos quais esses deixariam de prover o desenvolvimento e o bem-estar da criança/adolescente (considerando que poderiam fazer isso), em uma das seguintes áreas: saúde, educação, desenvolvimento emocional, nutrição, abrigo e condições seguras. Considerando que tais órgãos desempenham papel relevante e normatizador na área, no presente estudo adota-se essa definição.

A ênfase nas várias dimensóes desenvolvimentais afetadas pela negligência parece inclusive concorrer para que alguns autores sugiram que a problemática seja pensada a partir da descrição de subtipos: a negligência física, a emocional e a educacional, na mesma linha de algumas publicaçóes internacionais (Glaser, 2002; Zuravin, 1999; Dubowitz; Pitts \& Black; 2004) Pires e Miyazaki (2005) explanam que: 
a) A Negligência fisica referir-se-ia a situaçōes em que a criança se apresenta quase sempre suja, e sua alimentação e vestimenta são insuficientes e inadequadas; ela passa longos períodos sozinha, sem cuidado ou supervisão de um adulto responsável; está mais suscetível a sofrer acidentes devido à falta de supervisão; tem problemas físicos ou necessidades médicas não atendidas ou padece da ausência de um seguimento médico periódico. Segundo os autores, deve-se considerar os casos os quais a situação é crônica e habitual, não decorrendo de uma situação familiar momentânea, como uma crise, ou as situaçóes decorrentes de condiçôes socioeconômicas adversas mais amplas, que atingem todos os membros da família (pobreza/miséria).

b) A Negligência psicológica, em seu turno, referir-se-ia às situaçôes em que, de modo repetitivo, expressóes emocionais e comportamentos da criança, visando proximidade e interaçáo com os pais/adultos responsáveis, não recebem atençáo; em alguns casos, a criança pode necessitar de cuidados psicológicos, mas há recusa ou atraso em buscar/oferecer esse tipo de acompanhamento a ela; ela é exposta frequentemente a situaçóes de uso abusivo de álcool e outras drogas, e/ou ao tabagismo (uso do cigarro), com a permissão para que também façam uso desse; e também é exposta frequentemente às brigas entre os adultos da família e/ou à violência conjugal. Nesse subtipo, notar-se-ia uma ausência de iniciativa de interação e contato por parte de alguma figura adulta responsável/estável com a criança. Haveria descaso por parte dos adultos da família em perceber as necessidades da criança e tentar atendê-las.

c) Quanto ao subtipo Educativo, esse referir-se-ia às situações em que seria notável o desengajamento, por parte de adultos responsáveis, demonstrando-se despreocupação com relação à promoção de comportamentos sociais positivos na criança, com relação à sua sociabilidade, falhando em supervisionar sua conduta, por exemplo, permitindo-lhe faltas crônicas à escola, deixando de acompanhar seu processo educacional por falta de atençấo específica às suas necessidades escolares, ou permitindolhe frequentar pares (amigos) com comportamento anti-social e/ou delinquente.

\section{Consequências da negligência infantil e relações com a deficiência}

A negligência parental pode ocasionar danos que podem levar até ao óbito, outros casos podem gerar consequências, como alguma deficiência à criança sob seus cuidados (CRUZ; SILVA; ALVES, 2007; LACHARITÉ; ETHIE; NOLIN, 2006; NOLIN; TURGEON, 2004; PASIAN, 2004; ZIELINSKI, 2009). Salienta-se que a negligência infantil envolve aspectos mais amplos que os cuidados diretos dos pais (apesar de sempre estarem presentes), pois os mesmos precisam de envolvimento social e governamental que auxiliem e que forneçam possibilidades para o cuidado das crianças em diversos setores, como saúde e educação entre outros. Como afirma Pasian (2004), é preciso primeiro investir na promoção da saúde para prevenir que possíveis deficiências ocorram, pois muitas são geradas por problemas que podem ser evitados. É necessário orientar os pais para que eles possam cuidar adequadamente de seus filhos, pois diversos fatores podem prevenir a deficiência, entre eles estão:

- Saneamento básico e educação sanitária, isso pode evitar diversas doenças que podem causar danos irreversíveis ou mesmo a morte; 
- Proteção contra-acidentes, muitos destes podem e devem ser evitados com orientaçôes e materiais adequados de proteção;

- Evitar doenças contagiosas através de vacinação, orientação e divulgação;

- Tratar da cura das doenças o mais cedo possível, buscando-se diagnósticos precoces, podendo assim evitar consequências irreversíveis;

- Exames realizados no nascimento dos bebês podem servir para a descoberta de alguma anormalidade com necessidade de tratamento, a qual descoberta a tempo e tratada pode evitar uma futura deficiência. Como por exemplo, o teste do "pezinho", ou testes que podem diagnosticar uma futura surdez ou cegueira;

- A orientação aos pais sobre o pré-natal e os cuidados básicos que devem ter com o bebê pode evitar que ele se torne um futuro portador de alguma deficiência;

Portanto, faz-se necessário investir primeiro nos aspectos que podem evitar a deficiência, que envolve os pais/cuidadores, mas que são de responsabilidade dos órgãos públicos em oferecer meios de viabilizar os cuidados necessários e alertar para precauções e informaçôes à população. Muitos pais são negligentes por não ter orientação e/ou recursos às necessidades de seus filhos.

Tratando especificamente da negligência, tal problemática tem sido muitas vezes considerada uma forma menor de maus-tratos, pois não comporta uma forma de agressão contra uma criança, mas sim, a ausência de comportamentos que caracterizam a falta de respostas no sentido de prover as necessidades essenciais da criança. No entanto, os efeitos negativos da negligência no desenvolvimento da criança, de acordo com as investigaçôes específicas, são graves e merecem uma atenção especial. Investigaçôes em diferentes países revelam que a negligência está associada a muitos danos ao desenvolvimento da criança, muitas vezes pode ocasionar lesôes que irão perpetuar na forma de alguma deficiência ou mesmo no óbito da criança, sobretudo se vivenciada precocemente e de forma crônica (GLASER, 2002; LACHARITÉ; ÉTHIER; NOLIN, 2006; NOLIN; TURGEON, 2004; WILLIAMS, 2003; ZIELINSKI, 2009).

\section{Método}

Serão apresentados, a seguir, alguns apontamentos sobre a negligência, embasados em produção científica brasileira. Com a finalidade de mapear os avanços do conhecimento a respeito da negligência, procedeu-se, então, a um levantamento bibliográfico, recorreu-se às bases de dados SciELO (Scientific Eletronic Library Online) e LILACS (Literatura Latino-americana e do Caribe em Ciências da Saúde). O levantamento foi realizado sem restrição de período, foram levantados os artigos disponíveis desde o início das bases de dados citadas até o ano 2012, os artigos selecionados situam-se entre 2000 e 2010.

O critério para a seleção dos artigos foi conter os descritores "maus-tratos \& infantis \& negligência" ou "maus-tratos \& negligência \& criança”, alternados com os 
descritores "consequência", "impacto", "desenvolvimento" e "aprendizagem”, sendo que os mesmos podiam estar dispostos em qualquer parte do texto. Identificados os trabalhos, foram selecionados para análise aqueles que se encontravam disponíveis em formato de textos completos, permitindo adequado exame e síntese informativa.

$\mathrm{Na}$ base de dados SCIELO, foram encontrados apenas dois artigos completos sobre negligência. $\mathrm{Na}$ base de dados LILACS, foram encontrados 14 artigos completos, totalizando-se 16 artigos. Estes artigos foram cruzados para eliminar os repetidos (apenas um), o que resultou em 15 artigos nacionais disponíveis com texto completo nestas bases de dados científicos. Em seguida foi feita verificação do conteúdo dessas publicaçôes, buscando-se averiguar o quanto eram compatíveis ao foco do presente estudo (negligência). Desta forma, foram selecionados 12 artigos, sendo que foram excluídos aqueles que não tratavam do tema proposto ou que eram específicos em uma modalidade de maus-tratos que não era a negligência.

Quando adicionado os descritores "deficiência" ou "necessidades especiais" nenhum artigo foi encontrado nas bases de dados. No entanto, apesar de não aparecerem na busca com os descritores, quando lido os artigos e visto as referências bibliográficas, foi possível constatar que dois artigos nacionais relacionam a temática de maus-tratos infantis com deficiência, um de autoria de Williams (2003) e o outro de Cruz, Silva e Alves (2007), sendo realizado um relato das informaçôes contidas nesses artigos que relaciona a negligência e a deficiência.

\section{Resultados}

Será apresentado um relato do que os artigos levantados abordaram de forma geral na revisão bibliográfica (GRANVILLE-GARCIA; et al., 2009; GONÇALVES, FERREIRA, MARQUES, 2002; MARTINS, 2010; MATIAS, BAZON, 2005; SILVA; FERRIANI, 2007; VAGOSTELLO; et al., 2003). Os artigos se situam basicamente sobre a temática da notificação e definição das formas de maus-tratos infantis, observando que não foram encontradas mençáo sobre medidas de prevenção e programas de orientação para os pais/cuidadores dentro da realidade brasileira. Em seguida, discorre-se sobre os dois artigos que enfocaram a temática da relaçáo entre maus-tratos infantis e deficiência (CRUZ; SILVA \& ALVES, 2007; WILLIAMS, 2003).

\section{Detecção e notificação da negligência infantil}

Os artigos relatam que as estatísticas de maus-tratos, incluindo a modalidade negligência, são escassas, referindo-se, em geral, somente aos casos registrados nas instâncias oficiais de proteção infantil, como encontrado nos artigos de Martins (2010); Matias e Bazon (2005); Gonçalves, Ferreira e Marques (2002). Martins (2010) também mostra, em uma revisão da literatura sobre os maus-tratos contra crianças e adolescentes, que além da falta de notificação por parte de profissionais e da sociedade, os serviços para identificação e atendimento das vítimas são poucos e não possuem uma rede de informaçấo interligada para averiguar os casos. 
Do ponto de vista social, os maus-tratos contra a criança passaram a merecer maior atenção no final dos anos 80. Nessa época, o problema foi abordado na Constituição Federal (BRASIL, 1988) e no Estatuto da Criança e do Adolescente (ECA) (BRASIL, 1990), que tornaram obrigatória a notificação de casos de maus-tratos conhecidos, suspeitos ou confirmados (art. 13 do ECA), prevendo sansôes para os médicos, professores e responsáveis por estabelecimentos de Saúde e de Educação que deixassem de fazê-lo (art. 245 do ECA). No estado de São Paulo, em janeiro de 2000, foi promulgada a Lei n. 10.498, que também dispóe sobre a obrigatoriedade de notificação de casos suspeitos ou confirmados de maus-tratos em crianças e adolescentes, pelos órgãos públicos das áreas de Saúde, Educação e Segurança Pública, envolvendo diretamente o médico, o professor, os responsáveis pelos estabelecimentos de saúde, de ensino fundamental, pré-escola ou creche e delegacias de polícia (PASIAN, 2012).

A escola (o setor educacional) é considerada um local ideal para a detecção das crianças negligenciadas, pois o tempo que a criança passa na escola e o convívio com professores podem facilitar a percepçáo dos casos. Alguns trabalhos começaram a ser realizados, nesse sentido, desenvolvendo cartilhas e questionários para conscientizar e preparar os professores para que sejam capazes de fazer os assinalamentos dos casos (a notificaçáo), pois sabe-se que a escola, apesar da obrigatoriedade em notificar os casos suspeitos, o fazem de forma muito tímida (BAZON, 2008). Quando estudado a realidade brasileira, Bazon (2008) coloca que os educadores/professores brasileiros suspeitam de um número significativo de casos de crianças que podem estar sofrendo maus-tratos, mas poucos são aqueles notificados, valendo frisar que a maioria dos casos suspeitos seria, por eles, classificados como sendo de negligência.

As razões pelas quais os educadores/professores não notificam são muitas e encontram-se indicadas na literatura (GRANVILLE-GARCIA; et al., 2009; SILVA; FERRIANI, 2007; VAGOSTELLO; et al., 2003). Sabe-se que uma proporção dos casos que não são notificados deve-se ao fato desses não serem considerados "tão graves". Essa percepção de "pouca gravidade", em geral, refere-se a modalidades de maus-tratos que não deixam marcas físicas no corpo da criança ou qualquer outro tipo de sequela dessa natureza, o que abarca sobremaneira os casos de negligência. Outro fator importante, indicado na literatura, que influi na tomada de decisão sobre notificar ou não um caso suspeito de maus-tratos às autoridades, no âmbito do setor educacional, é o medo de se envolver com a problemática, temendo que ocorram represálias por parte dos envolvidos (GRANVILLE-GARCIA; et al., 2009; SILVIA; FERRIANI, 2007, PASIAN, 2012).

\section{Relatos sobre a negligência infantil e deficiência}

Alguns artigos analisados, que envolveram descrição sobre deficiência ou necessidades especiais, se dirigiam a esses termos apenas para relatar que a deficiência pode ser adquirida perante as consequências que os maus-tratos infantis e a negligência infantil podem ocasionar. Apenas dois artigos abordam a relação da temática deficiência e maus-tratos infantis, colocando como destaque o tema da violência e deficiência, explorando essa relação, sendo um de Williams (2003), intitulado "Sobre deficiência e violência: reflexões para uma análise de revisão de área”, e o outro de 
Cruz, Silva e Alves (2007), em um estudo de revisão bibliográfica com o título "Evidências sobre violência e deficiência: implicaçôes para futuras pesquisas".

O artigo de Williams (2003) descreve sobre a inter-relação entre o fato de ser portador de deficiência e a temática da violência doméstica. A autora utiliza estudos de caso para ilustrar como a deficiência pode ser um resultado de atos de maus-tratos ou negligência. $\mathrm{O}$ estudo aborda três eixos de discussão, o primeiro, relativo à violência cometida pelo parceiro à mulher durante o período de gestação, salienta que no Brasil é difícil encontrar estudos sobre essa temática e que as consequências podem gerar sérios danos para a criança. O segundo eixo relata sobre como os maustratos e a negligência parental estão fortemente associados a danos graves para o desenvolvimento infantil, sendo que a literatura é ampla sobre o abuso sexual infantil, revelando diversas sequelas causadas advindas do mesmo. Por último, relata sobre a grande vulnerabilidade do indivíduo com necessidades especiais, podendo ser vítima de violência e também, em alguns casos, pode ser agressor, sendo que alguns pais com deficiência intelectual apresentam maior probabilidade de maus tratos aos filhos (WILLIAMS, 2003).

Williams (2003, p. 151) coloca em seus comentários finais a necessidade de medidas de prevenção para combater a violência doméstica como medida de prevenção à deficiência em alguns casos: "Prevenir e combater a violência doméstica significa prevenir, também, a ocorrência ou o agravamento de deficiências, seja em termos de prevenção primária, secundária ou terciária”. De acordo com a Organização Mundial da Saúde, a prevenção primária objetiva a eliminação ou redução de fatores sociais, culturais e ambientais que favorecem os maus-tratos; a prevenção secundária tem como objetivo a detecção precoce de crianças em situaçóes de risco, impedindo atos de violência e/ou sua repetição e a prevenção terciária que acompanha de forma integral a vítima e o agressor com a intenção de reabilitação e tratamento. A autora faz, também, uma colocação sobre o documento publicado pela Associação de Psicologia Americana (APA 2003), o qual revela que há pouca articulação, incluindo o Brasil, entre as entidades de proteção à criança e as organizaçóes que fornecem atendimento na área de educação especial.

O artigo de Cruz, Silva e Alves (2007) aborda o fenômeno da violência e suas relaçóes com a deficiência no desenvolvimento humano, onde foram levantados estudos sobre os tipos de violência e suas relaçóes com a deficiência. Para isso foi realizada uma revisão de literatura em bases de dados entre os anos de 2005 e 2006, sendo considerados como fonte da coleta de dados artigos de periódicos e livros.

Um dos aspectos relatados pelos autores sobre essa temática na realidade brasileira foi que (CRUZ; SILVA; ALVES, 2007):

Atualmente no Brasil, tem-se voltado a atenção para a exposição e suscetibilidade crescente da violência nos seus mais diversos tipos e na frequência em que esta ocorre no cotidiano da comunidade. No campo da pesquisa, evidências trazem conceitos, classificaçóes, tendências e repercussóes da violência na saúde humana, o que 
permite fazer uma projeção de seu impacto sobre as condiçôes de educação, saúde e também de deficiências que possam surgir a partir dela. (CRUZ; SILVA; ALVES, 2007, p. 132).

Cruz, Silva e Alves (2007) seguem fazendo um relato dos conceitos de violência, sendo que a mesma pode ser classificada de acordo com as definiçóes da Organização das Naçóes Unidas para a Educação, a Ciência e a Cultura (UNESCO, 2002):

- Violência direta, podendo ser física, sexual ou negligência, sendo que pode causar danos irreparáveis à vida do indivíduo, como na saúde, na liberdade e consequentemente na vida;

- Violência indireta: que pode ser através de açóes coercitivas ou agressivas, que impliquem em prejuízo psicológico ou emocional;

- Violência econômica: que envolve danos causados ao patrimônio, podendo ser através de atos de delinquência e criminalidade;

- Violência moral ou simbólica: onde a violência é gerada por algum tipo de autoridade, abrange as relaçóes de poder interpessoais ou institucionais que cerceiam a livre ação, pensamento e consciência do indivíduo

O estudo de Cruz, Silva e Alves (2007) aborda também a relação entre os problemas econômicos e sociais e a violência, principalmente na realidade brasileira, onde as diferenças sociais são imensas e muitas vezes as famílias menos favorecidas financeiramente não conseguem dispor de serviços de apoio, educação, saúde e educação. Os autores relatam:

$\mathrm{Na}$ literatura brasileira a associação entre a violência e as dinâmicas sociais são bastante discutidas. A pobreza, o desemprego, as crises econômicas, as desigualdades sociais, são alguns dos eventos sociais mais debatidos no que se refere ao fenômeno da violência na sociedade. (CRUZ; SILVA; ALVES, 2007, p. 133).

Os autores continuam com um relato da exclusão pela violência, mostrando que a história revela um elo entre violência e deficiência, sendo que algumas culturas, como a grega, matavam os recém-nascidos que tivessem alguma deficiência física, o que regia era a valorizaçáo do indivíduo forte, saudável e corajoso. A seguir, é descrito o mesmo tópico abordado por Williams (2003), relatando sobre a violência praticada contra a mulher durante a gestação, mostrando as deficiências como consequência dessa violência. Os autores enfatizam:

Fica claro, por diversos indicadores, que a violência contra a gestante pode repercutir em uma gestação traumática, tanto no aspecto físico quanto no emocional, o que sinaliza que as consequências da violência se projetam náo somente na mãe, mas sobre o desenvolvimento gestacional. Deste modo, a ocorrência da violência durante a gestação pode ocasionar alteraçôes embrionárias e fetais, com consequente nascimento de crianças com sequelas físicas, mentais e atrasos globais no desenvolvimento. (CRUZ; SILVA; ALVES, 2007, p. 136). 
O tema sobre a deficiência gerada por maus-tratos e negligência dos pais vem em seguida, onde os autores relatam diversos estudos que abordam essa temática. Os autores enfocam sobre as consequências negativas da exposição à violência e da negligência, que gera sequelas negativas em diversas áreas do desenvolvimento infantil e vem sendo relatado em diversos estudos internacionais, mas com escassez na realidade brasileira. Os autores abordam, ainda, a temática do impacto do abuso sexual infantil no desenvolvimento, os quais podem causar impacto a curto e longo prazo e, por último, alertam para a vulnerabilidade por parte do portador de deficiência. Como enfatizado pelos autores (CRUZ; SILVA; ALVES, 2007, p. 143): "a deficiência pode ser um fator que favorece a exposição à violência. A pessoa com deficiência pode se ver mais facilmente diante de situaçóes abusivas das quais pode não saber se proteger".

\section{Conclusões}

A negligência infantil pode acarretar a deficiência por faltas de medidas de prevenção como a aplicação de vacinas ou cuidados médicos e, depois de adquirida a deficiência, a negligência parental pode comprometer ainda mais o desenvolvimento da criança se não receber os cuidados necessários e essenciais. Portanto, fazem-se necessárias medidas que auxiliem e orientem toda a sociedade e proporcionem apoio para que os pais possam cuidar adequadamente de seus filhos. Destaca-se que investimentos sociais e governamentais são necessários para os cuidados das crianças, principalmente nos setores de saúde e educação, criando condiçôes para que os pais tenham acesso e orientação aos serviços de prevenção e cuidados para seus filhos.

Muitos pais, ao descobrirem que seu filho possuiu algum tipo de deficiência, apresentam reaçôes de choque, depressão materna ou rejeição, muitas vezes não fornecendo de forma adequada oportunidades para um bom desenvolvimento da criança, como tratamento e intervenção (WILLIAMS, 2003). Quando a deficiência existe é preciso buscar medidas que auxiliem o cuidado adequado e promovam o melhor atendimento possível, sendo que medidas preventivas podem ter efeitos importantes no desenvolvimento infantil (PASIAN, 2004; GLASER, 2002; LACHARITÉ; ÉTHIER; NOLIN, 2006).

Os estudos na realidade brasileira mostram que ainda há pouca notificação dos casos de maus-tratos infantis e que isso precisa ser mudado, pois para que medidas preventivas sejam tomadas e programas de orientação sejam efetuados, é necessário, primeiramente, que os casos de negligência ou abuso infantil sejam informados e conhecidos. Destaca-se que as crianças negligenciadas tendem a acumular problemas desenvolvimentais múltiplos e suas capacidades adaptativas são precárias (GLASER, 2002; LACHARITÉ; ÉTHIER; NOLIN, 2006; NOLIN; TURGEON, 2004). Muitas dessas crianças, ao entrarem na escola, apresentam dificuldades de aprendizagem e de comportamento e, por essa razão, devem ser alvo de intervenção de ajuda, visto que têm chances de desencadear uma série de novas consequências negativas (LACHARITÉ; ÉTHIER; NOLIN, 2006; GRASSI; ASHY; STEIN, 2008; WILSON; WIDOM, 2008; WRIGHT; CRAWFORD; DEL CASTILLO, 2009; ZIELINSKI, 2009). 
Apenas dois artigos abordaram a temática sobre a relação de maus-tratos infantis e deficiências, mostrando que a violência doméstica é um grave fator de risco para o desenvolvimento infantil e que pode ocasionar sequelas severas que podem perpetuar por toda a vida. Os dois artigos enfocaram mais a temática da violência sexual, não fazendo uma abordagem da negligência especificamente.

Pode ser verificado que há necessidade de mais estudos sobre maus-tratos infantis, especificamente na modalidade da negligência que envolva a temática da deficiência, pois não foi encontrado qualquer artigo que envolva negligência infantil e deficiência. Ressalta-se que existe uma relação tanto da deficiência como fator de risco para a negligência, como a negligência podendo ser a causadora da deficiência.

\section{Referências}

AMERICAN Psychological Association (APA). Resolution on the maltreatment of children with disabilities. 2003.

BAZON, M. R. Violências contra crianças e adolescentes: análise de quatro anos de notificaçôes feitas no Conselho Tutelar na cidade de Ribeirão Preto, São Paulo, Brasil. Cadernos de Saúde Pública, Rio de Janeiro, v. 24, n. 2, p. 323-332, 2008.

BRASIL. Constituiçáa (1988). Constituiçấo da República Federativa do Brasil. Brasília, DF: Centro Gráfico, 1998.

BRASIL. Lei n. 8.069, de 13 de julho de 1990. Dispóe sobre o Estatuto da Criança e do Adolescente e dá outras providências. Diário Oficial da Uniāo, Brasília, DF, 16 jul. 1990. Seção 1, p. 13563, 1990.

CRUZ, D. M. C.; SILVA, J. T.; ALVES, H. C. Evidências sobre violência e deficiência: implicaçóes para futuras pesquisas. Revista Brasileira de Educação Especial, Marília, v. 13, n. 1, p. 131-146, 2007.

DUBOWITZ, H., PITTS, S. C.; BLACK, M. Measurement of three major subtypes of child neglect. Child Maltreatment, v. 9, n. 4, p. 344-356, 2004.

FERREIRA, A. L. Acompanhamento de crianças vítimas de violência: desafios para o pediatra. Jornal de Pediatria, Rio de Janeiro, v. 81, n. 5, p. 173-180, 2005.

GLASER, D. Emotional abuse and neglect (psychological maltreatment): a conceptual framework. Child Abuse $\&$ Neglect, Oxford, v. 26, p. 697-714, 2002.

GONÇALVES, H. S.; FERREIRA, A. L.; MARQUES, M. J. V. Avaliação de serviço de atenção a crianças vítimas de violência doméstica. Revista de Saúde Pública, São Paulo, v. 33, n. 6, p. 47-53, 2002.

GRANVILLE-GARCIA, A. F.; et al. Conhecimentos e percepção de professores sobre maus-tratos em crianças e adolescentes. Saúde e Sociedade, São Paulo, v. 18, n. 1, p. 131-140, 2009.

GRASSI, O. R.; ASHY, M.; STEIN, L. M. Psychobiology of childhood maltreatment: effects of allostatic load? Revista Brasileira Psiquiatria, São Paulo, v. 30, n.1, p. 60-68, 2008.

LACHARITÉ, C.; ÉTHIER L.; NOLIN, P. Vers une théorie écosystémique de la négligence envers les enfants. Bulletin de Psychologie, Paris, v. 59, n. 4, p. 381-394, 2006.

MARTINS, C. B. G. Maus tratos contra crianças e adolescentes. Revista Brasileira de Enfermagem, Brasília, DF, v. 63, n. 4, p. 660-665, 2010.

MATIAS, A. S. A.; BAZON, M. R. Maus-tratos de crianças de 0 a 6 anos que frequentam estabelecimentos de educação infantil na cidade de Ribeirão Preto. In: PROGRAMA de Pós-Graduação em Psicologia: livro de artigos. Ribeirão Preto: Légis Summa, v. 2, p. 287-298, 2005.

NOLIN, P.; TURGEON, M. Relation entre la négligence et la capacité de mémorisation et d'apprentissage verbal chez les enfants. Revue Québécoise de Psychologie, Trois Rivières, v. 25, n. 2, p. 151-165, 2004.

PASIAN, M. S. Maus-tratos infantis: o impacto da negligência no desenvolvimento psicossocial e acadêmico de crianças em fase inicial de escolarização.USP - Ribeirão Preto, 144 p., 2012. 
PASIAN, M. S. Educação especial: a prevenção das deficiências e a busca de melhoras para amenizar a deficiência adquirida. Psicopedagogia onLine: Educação \& Saúde Mental, www.psicopedagogia.com.br, 2004.

PASIAN, M. S; et al. Negligência infantil a partir do Child Neglect Index aplicado no Brasil. Psicologia, Reflexão e Crítica, v. 28, n.1, p. 106-115, 2015.

PIRES, A. L. D.; MIYAZAKI, M. C. O. Maus-tratos contra crianças e adolescentes: revisão da literatura para profissionais da saúde. Arquivos de Ciências da Saúde, v. 12, n. 1, p. 42-49, 2005.

ROQUE, E. M. S. T.; FERRIANI, M. G. C. Estudo das famílias de crianças e adolescentes, vítimas de violência, que sofreram intervenção da justiça. Revista Latino-Americana de Enfermagem, Ribeirão Preto, v. 15, n. 4, p. 334-344, 2007.

SILVA, I. M. A.; FERRIANI, C. M. G. Violência doméstica: do visível ao invisível. Revista Latino-Americana de Enfermagem, v. 15, n. 2, 2007.

UNESCO (Organização das Naçóes Unidas para a Educação, a Ciência e a Cultura). Abramovay, M. Juventude, violência e vulnerabilidade social na América Latina: desafios para políticas públicas Brasília: UNESCO, 192p, 2002.

VAGOSTELLO, L.; et al. Violência doméstica e escola: um estudo em escolas públicas de São Paulo. Paidéia (Ribeirão Preto), v. 13, p. 190-196, 2003.

WILLIAMS, L. C. A. Sobre deficiência e violência: reflexôes para uma análise de revisão de área. Revista brasileira de educaçáo especial, v. 9, n. 2, p. 141-154, 2003.

WILSON, H. W.; WIDOM, C. S. A Prospective examination of the path from child abuse and neglect to illicit drug use in middle adulthood: the potential mediating role of four risk factors. Journal of Youth and Adolescence, New York, v. 38, n. 3, p. 340-354, 2008.

WORLD Health Organization; International Society For Prevention Of Child Abuse And Neglect (WHO/ IPSCAN). Preventing child maltreatment: a guide to taking action and generating evidence, 2006. Disponível em: <http://www.ispcan.org/publications.htm>. Acesso em: $10 \mathrm{dez} .2011$.

WRIGHT, M. O.; CRAWFORD, E.; DEL CASTILLO, D. Childhood emotional maltreatment and later psychological distress among college students: the mediating role of maladaptive schemas. Child Abuse 8 Neglect, Oxford, v. 33, p. 59-68, 2009.

ZIELINSKI, D. S. Child maltreatment and adult socioeconomic well-being. Child Abuse \& Neglect, Oxford, v. 33, n. 10, p. 666-678, 2009.

ZURAVIN, S. J. (1999). Child Neglect: A review of definitions and measurement research. In: DUBOWITZ, H. Neglected Children. Research, Practice and Policy. Sage Publications.

\section{Correspondência}

Mara Silvia Pasian - Universidade Federal de São Carlos, Centro de Educação e Ciências Humanas. Rodovia Washington Luís, km 235 - SP-310, CEP: 13565-905. São Carlos, São Paulo - Brasil.

E-mail: marasilvia123@yahoo.com.br

Recebido em 01 de fevereiro de 2014

Aprovado em 14 de abril de 2015 